\title{
Design of an Axisymmetric Afterbody Test Case for CFD Validation
}

\author{
Kevin J. Disotell ${ }^{*}$ and Christopher L. Rumsey ${ }^{\dagger}$ \\ NASA Langley Research Center, Hampton, Virginia, 23681
}

\begin{abstract}
As identified in the CFD Vision 2030 Study commissioned by NASA, validation of advanced RANS models and scale-resolving methods for computing turbulent flow fields must be supported by continuous improvements in fundamental, high-fidelity experiments designed specifically for CFD implementation. In accordance with this effort, the underpinnings of a new test platform referred to herein as the NASA Axisymmetric Afterbody are presented. The devised body-of-revolution is a modular platform consisting of a forebody section and afterbody section, allowing for a range of flow behaviors to be studied on interchangeable afterbody geometries. A body-of-revolution offers advantages in shape definition and fabrication, in avoiding direct contact with wind tunnel sidewalls, and in tail-sting integration to facilitate access to higher Reynolds number tunnels. The current work is focused on validation of smooth-body turbulent flow separation, for which a sixparameter body has been developed. $A$ priori RANS computations are reported for a riskreduction test configuration in order to demonstrate critical variation among turbulence model results for a given afterbody, ranging from barely-attached to mild separated flow. RANS studies of the effects of forebody nose (with/without) and wind tunnel boundary (slip/no-slip) on the selected afterbody are presented. Representative modeling issues that can be explored with this configuration are the effect of higher Reynolds number on separation behavior, flow physics of the progression from attached to increasingly-separated afterbody flows, and the effect of embedded longitudinal vortices on turbulence structure.
\end{abstract}

\section{Nomenclature}

$\langle\bullet\rangle$

$=$ mean value of parameter inside brackets

$a \quad=$ speed of sound

$C_{f} \quad=$ local skin-friction coefficient

$C_{p} \quad=$ local pressure coefficient

$L \quad=$ axial length of body (no subscript); axial length of body section (subscripted)

$M \quad=$ Mach number, ratio of velocity magnitude to speed of sound reference

$p \quad=$ pressure

$R \quad=$ local radius of body

Re $\quad=$ Reynolds number based on $R_{\max }, R e=U_{\infty} R_{\max } / v$

$T=$ temperature

$U=$ mean flow velocity component in $x$-direction

$u^{\prime} \quad=$ fluctuating velocity component in $x$-direction

$w^{\prime} \quad=$ fluctuating velocity component in $z$-direction

$x=$ Cartesian coordinate along body axis of revolution

$z=$ Cartesian coordinate normal to axis of revolution on $y=0$ plane

$\delta=$ local boundary-layer thickness at $0.99 U_{e}$

$\eta \quad=$ distribution of body radius along axis of revolution, $R(x)$

$\kappa=$ longitudinal curvature of surface definition

$v \quad=$ kinematic viscosity of fluid

\footnotetext{
* NASA Postdoctoral Program Fellow, Flow Physics and Control Branch, MS 170, AIAA Member.
}

$\uparrow$ Senior Research Scientist, Computational AeroSciences Branch, MS 128, AIAA Fellow. 
$\sigma \quad=\quad$ ratio of aftbody radius to maximum body radius;

also, standard deviation of parameter $Q$ notated by $\sigma(Q)$

\begin{tabular}{|c|c|c|}
\hline \multicolumn{3}{|c|}{ Subscripts } \\
\hline $\bar{A}$ & $=$ & constant-radius aftbody section \\
\hline$B$ & $=$ & boattail section \\
\hline$e$ & $=$ & value at edge of boundary layer \\
\hline$F$ & $=$ & constant-radius forebody section \\
\hline $\max$ & $=$ & global maximum of parameter \\
\hline$N$ & $=$ & nose section \\
\hline peak & $=$ & local maximum of parameter \\
\hline$t$ & $=$ & stagnation conditions \\
\hline$\infty$ & $=$ & value far upstream of body \\
\hline \multicolumn{3}{|c|}{$\underline{\text { Superscripts }}$} \\
\hline+ & & viscous sublayer-scaled value \\
\hline
\end{tabular}

\section{Introduction}

$\mathrm{T}$ HE CFD Vision 2030 study $^{1}$, commissioned by NASA to develop a plan for research investments in simulation-based engineering processes relevant to the aerospace industry, underscored the lack of current reliability in deploying computational fluid dynamics (CFD) to a wide operational design space. In particular, a pervasive issue has been the prediction of viscous flow fields over streamlined bodies with turbulent flow separation present. Besides the inability to accurately predict vehicle drag for arbitrary operating conditions a priori, low confidence in edge-of-the-envelope performance predictions can misguide design decisions or defer to overly conservative approaches that sacrifice performance. To further develop, diagnose, and correct advanced physicsbased CFD methods for computing turbulent flows, high-fidelity benchmark experiments to be coordinated by NASA were recommended by the CFD Vision 2030 study. In doing so, new validation databases are in the process of being generated for use as community resources to aid modelers; one such effort already underway is the NASA Juncture Flow Experiment. ${ }^{2}$

In order to critically assess the accuracy of a simulation and its modeling components, the most basic requirement for a validation experiment is a reproducible set of boundary values for the flow physics of interest. Only then can it be assured that a computation is posing the same question of nature as in the "truth" case, which may be a physical experiment or a fully-resolved numerical simulation (e.g., direct numerical simulation). Oberkampf and Roy $^{3}$ define validation programs as a unique class of experiment: "...a validation experiment is designed, executed, and analyzed for the purpose of quantitatively determining the ability of the model and its embodiment in a computer code to simulate a well-characterized physical process." For turbulent flows in particular, the difficulty of full characterization is writ large given the range of interacting length and velocity scales in the flow. Thus, the accessibility of measurements also becomes a defining quality of the validation effort. Oberkampf and Roy ${ }^{3}$ further describe a hierarchy of validation experiments in terms of physical characteristics and extent of measured data. This hierarchy ranges from unit problems with simple hardware providing isolated physics and the highest level of measurement detail, to complete production systems with full physics but more limited measurement data. All levels contribute insight to design tool validation.

The current work addresses the design and ongoing execution of a new test platform for turbulence modeling validation in wall-bounded flows with separation. A discussion of the philosophy and approach to the test case design is presented. Details on the devised body-of-revolution formulation are then documented, including parameters for a prototype configuration developed for risk-reduction testing. Early-stage CFD results comprising a sensitivity study on the effect of a priori turbulence model selection on flow behavior for this risk-reduction configuration are presented and discussed. Finally, conclusions drawn from the computational results are summarized to guide a path forward for obtaining a "truth" case requiring experimental and/or direct simulation data.

\section{Test Case Development}

In this section, the requirements and philosophy underpinning the test case design are documented. The particular focus of the validation effort is described, leading to a discussion of the designed test configuration. 
Derivation of the body geometry is presented, followed by a description of the integral flow physics relevant to the test case. Finally, industry-relevant applications of the test geometry are highlighted for practical motivation.

\section{A. Requirements}

Of primary interest for turbulence modeling purposes was the ability to produce a range of cases encompassing attached turbulent flow, incipient turbulent separation, and large-scale separation from a smooth surface. Accordingly, a simple mechanism that could be unambiguously duplicated between the experiment and computation was necessary to vary the scale of separation, which amounts to varying the adverse pressure gradient for the desired smooth-body separation. The surface geometry was desired to be relatively simple, such that it could be exactly defined using analytic functions for unambiguous representation by CFD; a two-dimensional or axisymmetric geometry was preferable. This approach was aimed at reducing numerical error due to uncertainty in the geometry definition. Also pertaining to grid considerations, the wind tunnel wall constraints were required to be unambiguously reproduced without undue complexity. The test conditions were to be at sufficiently high freestream Mach number to avoid the use of low-speed CFD preconditioners in compressible flow solvers, which typically suggests $M_{\infty}>0.1$.

\section{B. Configuration Decisions}

Given the above requirements, early test article concepts turned toward an axisymmetric configuration for several reasons. An axisymmetric body can be mounted more easily than a plane-symmetric model in a larger range of wind tunnel facilities, enabling a wider validation domain in Mach and Reynolds number. In addition, maintaining an accurate surface definition is accomplished more cost-effectively by the turning operation on a lathe compared to the fabrication process required for plane-symmetric models. As an example, Watson et al. ${ }^{4}$ cited these reasons for the choice of an axisymmetric test model to obtain two-dimensional boundary-layer data in a highReynolds-number cryogenic wind tunnel. Axisymmetric bodies-of-revolution with separation present have also been tested at high Reynolds number ${ }^{5}$, although the data typically consist of pressure coefficient distributions and qualitative surface visualizations rather than detailed flow turbulence measurements. Another advantage of an axisymmetric configuration is avoidance of direct contact between the test model and wind tunnel wall boundarylayers, commonly referred to as "3-D contamination" in plane-symmetric flows aiming for two-dimensional characteristics. This source of three-dimensionality can present ambiguous interference effects for floor-mounted and sidewall-mounted models. Finally, with increasing miniaturization of laser-based measurement systems, a suitably-sized axisymmetric model may also facilitate stowing of measurement equipment in the interior volume of a test body to enable highly-resolved, near-wall turbulence data.

The above advantages motivated an early design decision to pursue an axisymmetric test model. A foundation of experiments exists for axisymmetric geometries in turbulence research, some of which have been recommended as test cases for large-eddy simulation (LES) validation. ${ }^{6}$ While not specifically considering flow separation, Winter, Rotta, and Smith ${ }^{7}$ studied a waisted body-of-revolution as an analog for a cambered delta wing. The axisymmetric body was deemed to be a more tractable measurement case than the delta wing by avoiding the presence of threedimensional wing cross-flows, since the streamline convergence/divergence distribution of the delta wing could be made analogous between the two configurations. The waisted body profile is shown in Fig. 1 for reference. The specific effort of Winter, Rotta, and Smith during the 1960s was focused on diagnosing the inability of existing turbulent boundary-layer calculation methods to correctly predict local skin friction in regions of mild adverse pressure gradient combined with streamline convergence near the waist of the body, and considered both subsonic and supersonic attached flow.

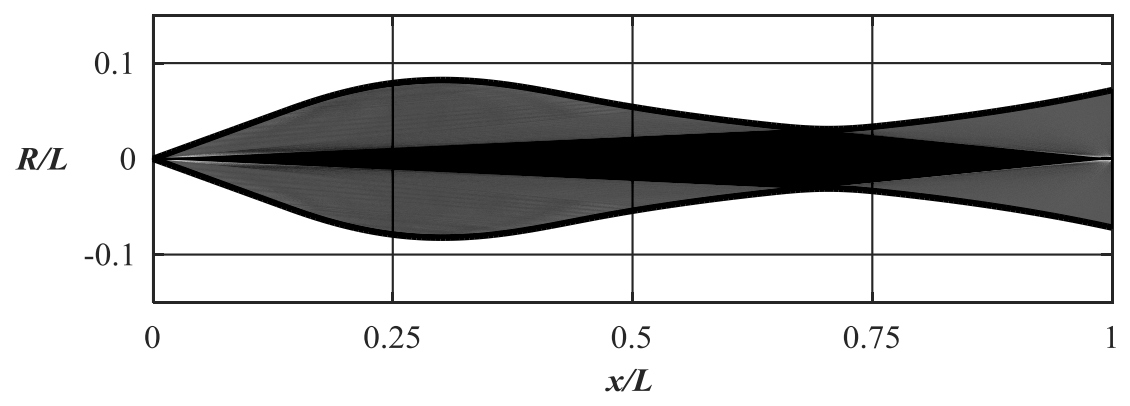

Figure 1. Waisted body-of-revolution profile from Winter, Rotta, and Smith. ${ }^{7}$ 
Particular to turbulent flows with separation, several axisymmetric experiments are noteworthy validation cases. Bachalo and Johnson ${ }^{8}$ contributed an advanced validation case in the 1980s for transonic shock/boundary-layer interaction consisting of an axisymmetric bump on a cylinder aligned with the flow direction, in which laser interferometry was deployed for detailed turbulence measurements. Driver ${ }^{9}$ reported detailed turbulence measurements in a mild separation bubble produced on a constant-diameter cylinder aligned with the direction of flow in a low-speed wind tunnel $(M=0.088$ at inlet). The cylinder occupied the entire streamwise length of the test section and was supported on both ends inside the contraction and diffuser sections of the wind tunnel. The adverse pressure gradient was supplied by diverging all four walls of the initially square test section. This test case included a careful check on axisymmetry of the flow field by quantitative circumferential pressure and skin friction measurements, as well as a momentum balance using velocity fields measured with a laser Doppler interferometer. Alving and Fernholz ${ }^{10,11}$ conducted detailed hot-wire/pulsed-wire anemometry measurements of turbulent boundary layer relaxation on a smooth, axisymmetric body following a short fetch of mean reversed flow under incompressible conditions.

Certain axisymmetric experiments have made use of interchangeable geometries to study a range of turbulent flow behavior near and beyond separation. Presz and Pitkin ${ }^{12}$ as well as Reubush and Putnam ${ }^{13}$ studied the compressible subsonic flow over a series of axisymmetric nozzle afterbody models, in which the exhaust plume was approximated by solid blockage in the form of an integrated tail sting. A range of attached, partially-separated and fully-separated flows was obtained by varying the mean angle of the contoured afterbody geometry and different contour shapes. In addition, the incoming turbulent boundary layer properties were parametrically varied by a modular forebody that could be extended in length over a constant-diameter section. Measurements of flow turbulence were not reported in either study. More recently, Hammache, Browand, and Blackwelder ${ }^{14}$ provided modern particle image velocimetry (PIV) measurements on an axisymmetric analog to a plane-symmetric Stratford ramp, inversely-derived from a pressure distribution yielding maximum pressure recovery over the shortest streamwise length while barely avoiding separation. Here, the nearly-separated flow exhibits both boundary-layer and wake-like behavior. Two additional ramp shapes with mean angles corresponding to higher and lower adverse pressure gradients were tested for comparison with the zero-skin-friction case. The theme of interchangeable test model stages to vary the scale of separation was appealing for the basis of the current test case design, as an accurate surface definition presents a reproducible boundary condition for CFD. From the aforementioned studies, it is noted that the body leading-edge was most often placed in the test section (other than the configuration of Driver ${ }^{9}$ ). This is both a practical aspect for installation in larger test facilities as well as a physical consideration for boundary-layer development on the test article.

\section{Test Model Geometry}

Specification of the test model geometry was guided by several design criteria: (1) minimal surface complexity; (2) a smooth, analytic surface definition to be unambiguously defined; and (3) an ability to parametrically vary the surface contour (and therefore, the flow behavior) through tailoring of the geometry inputs. The choice of an axisymmetric body-of-revolution offers the advantageous property of geometric two-dimensionality, thereby minimizing surface complexity. In determining an appropriate form of the shape-generating equation, it was desired to produce a continuous second derivative of the surface geodesic along the length of the body, as the flow may be sensitive to discontinuities in surface curvature.

To meet the intended requirements, an axisymmetric test body was devised to have four components: (1) an elliptical leading-edge nose, (2) a constant-radius forebody section, (3) a contoured boattail (ramp) section that is smoothly faired between the fore and aft sections, and (4) a constant-radius aft section. The mean boattail angle is a function of the ratio of aft-cylinder radius to maximum body radius, $\sigma$, as well as the desired axial length of the boattail section. The aft cylinder was desired to be as long as possible for studying relaxation of the perturbed flow over the ramp as well as reducing potential interference effects of the sting strut, which will be characterized during the initial stages of a planned risk-reduction experiment in a wind tunnel. A sample illustration of the parametric, axisymmetric body is shown in Fig. 2, with the above sections annotated. The axial length of the constant-radius forebody section may be adjusted to provide different incoming boundary layer conditions ahead of the boattail.

In order to satisfy the desire for a continuous second derivative of the surface geodesic, the constant-radius segments posed constraints for the generating equations of the elliptical nose and contoured boattail. The nose shape was selected to be a blended function between an ellipse and fourth-order superellipse, similar to that reported in Watson et $a l .{ }^{4}$ For the boattail, a fifth-order polynomial was selected for its capacity to support three inflection points, two of which are imposed at the end points of the contour to ensure that the first and second derivatives are zero. As formulated, the constructed shape requires a total of six geometric inputs: the maximum body radius, the 


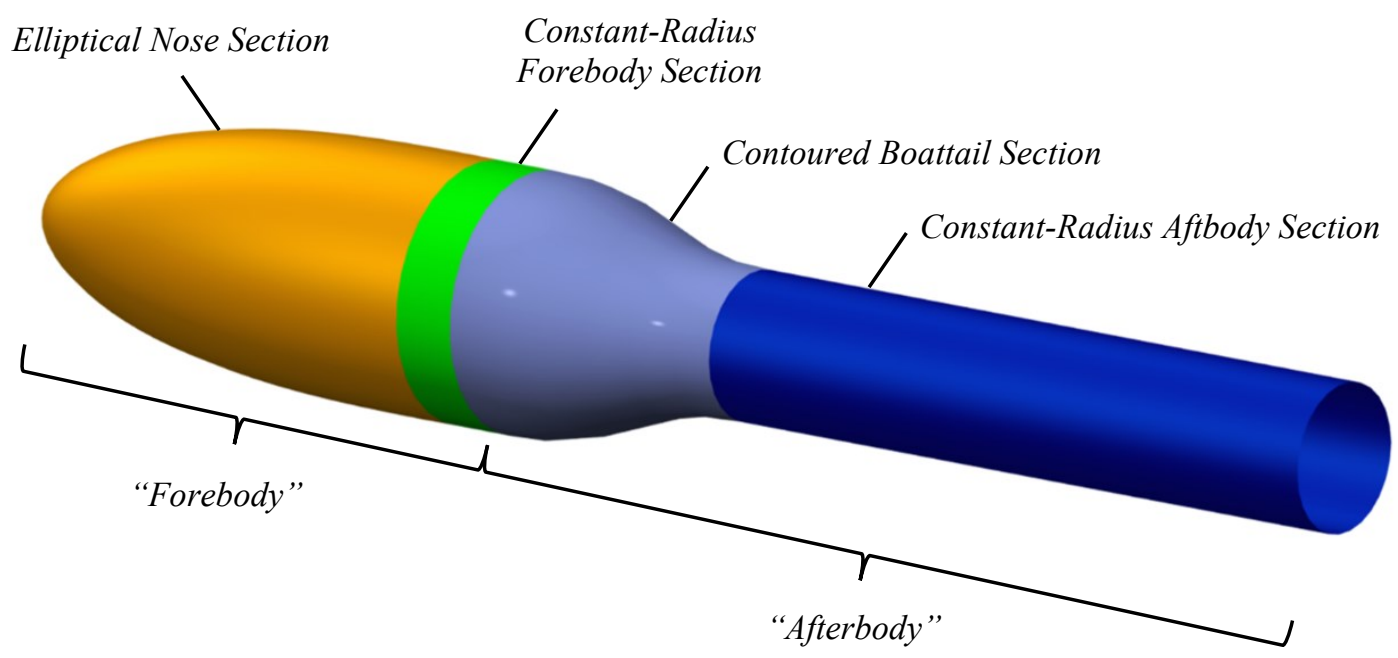

Figure 2. Rendering of isolated test body $(\sigma=0.575)$.

ratio of aftbody radius to maximum body radius, and axial lengths of the four individual stages previously described. The analytic formulation of this geometry is provided in the Appendix. Throughout this work, the axial origin of the coordinate system, $x=0$, is taken as the start of the defining equation for the boattail section; in other words, $x<0$ upstream of the boattail section.

Several of the geometric inputs were strategically selected for a prototype test model under development, which is referred to herein as a risk-reduction configuration. The length of the forebody was dictated by the minimum boundary-layer thickness accessible by measurement (taken to be $\sim 1 \mathrm{~cm}$ ), which was estimated with CFD calculations. A lower bound on the boundary-layer thickness is necessary for accurate characterization, but the boundary layer was desired to not be so thick relative to the body diameter as to separate with greater severity than is representative of full-scale wings. ${ }^{8}$ In addition, selection of the body size was guided by minimization of transverse curvature effects through the condition $\delta / R<<1$, where $\delta$ is the boundary layer thickness and $R$ is the local radius of the body, such that the local wall appears "flat" to turbulent eddies. Maximizing the body radius must be balanced by the practical requirement for an appropriate model scale for test and measurement, as well as avoidance of model sagging due to cantilevered weight. The latter aspect is critical to minimizing three-dimensional flow effects caused by model misalignment.

\section{Turbulence Modeling Aspects}

As Smits and Wood ${ }^{15}$ stated in their review of perturbed turbulent boundary layers, "The combined influence of different disturbances is rarely given by a simple summation of their separate effects." Additional physical effects may be produced by such interactions among multiple rates of strain, such as surface curvature or lateral divergence, thereby altering the turbulence structure and separation behavior. As new machine-based approaches to turbulence modeling are being explored ${ }^{16,17}$, appropriate training flows embodied in a core of validation experiments (physical or numerical) will be necessary, and by nature can be more conceptually adventurous for exploring complex flows in systematic ways. For the devised parametric body-of-revolution, the fundamental perturbations produced by the afterbody geometry include adverse pressure gradient, lateral streamline convergence, and longitudinal surface curvature (convex and concave, due to the chosen polynomial contour). Smits and Joubert ${ }^{18}$ have observed that the combined effect of convergence and convex curvature acts in a stabilizing manner by reducing turbulent mixing, whereas concave curvature by itself is destabilizing. Concave curvature may produce longitudinal roll cells ${ }^{15}$ akin to the Taylor-Görtler instability. The nature of curvature effects in particular, including magnitude and response time of flow parameters following the geometry perturbation, has been characterized to be asymmetric depending on whether the curvature is convex or concave. ${ }^{19}$ Given these ingredients, the case of attached flow over the boattail is expected to provide useful insight on its own. Modeling issues that can be assessed with this configuration framework are the effect of higher Reynolds number on separation characteristics, meaningful nonequilibrium effects associated with progression from attached to increasingly separated afterbody flows, and the effect of embedded mean flow vortices (e.g., Görtler vortices) on turbulence structure. 


\section{E. Practical Relevance of Configuration}

Axisymmetric afterbodies have been studied for decades due to their importance in the aerospace industry. In propulsion applications, nozzle afterbodies (boattails) can be a significant source of parasitic drag with flow separation present. For vehicle configurations with strong engine-airframe coupling, such behavior can strongly influence upstream flow conditions and overall aerodynamic performance. Flow separation at the aft end of aircraft fuselages is also a relevant application area for flow control technology. Finally, a class of space-launch vehicles known as "hammerheads"-with payload diameter larger than the rocket stage below it-have been the subject of buffet testing to quantify unsteady aerodynamic loading effects due to the diameter transition ${ }^{20}$, and recent simulations $^{21}$ of this configuration have been conducted. While axisymmetric afterbodies have been the focus of many empirical studies, much of the historical data are limited in spatial and/or temporal resolution. For the present work, the above considerations suggested a valuable opportunity to deploy modern experimental techniques to generate state-of-the-art experimental databases for CFD validation purposes on an industry-relevant geometry.

\section{A Priori Turbulence Model Results}

Development of the test case was supported by early-stage CFD guidance to demonstrate evidence for critical variations among turbulence models (e.g., barely-attached or mild separated flow) for a given configuration. In this section, details of the numerical setups are presented, followed by results from selected turbulence models for a riskreduction configuration. Effects of body nose geometry (with/without) and tunnel boundary-layer (with/without) are explored. The significance of the CFD results are discussed to inform future evolution of the test case.

\section{A. Computational Setups}

Steady RANS computations in fully-turbulent mode were pursued to inform the selection of mean boattail angle for the risk-reduction configuration and assess its potential for serving as a discriminating test case for turbulence models. For this purpose, the flow environment was modeled as a true axisymmetric domain with diameter equal to the size of the intended risk-reduction test facility. Initial risk-reduction work is planned for the closed-circuit NASA Langley 15-Inch Low-Speed Wind Tunnel, in which the test section is a square cross-section of side length 15.0 inches $(38.1 \mathrm{~cm})$. The physical corners of the test section were not considered in the computations at this stage. The flow conditions were $M_{\infty}=0.117$ at the test section inlet (corresponding to $U_{\infty}=40 \mathrm{~m} / \mathrm{s}$; maximum tunnel speed is 45 $\mathrm{m} / \mathrm{s})$, with Reynolds number based on maximum body radius $\left(R e=U_{\infty} R_{\max } / v\right.$, where $v$ is kinematic viscosity) of 180,000. The risk-reduction model geometry detailed in the Appendix is exclusively considered herein. As such, the geometric blockage (ratio of maximum cross-sectional area of the body to the cross-sectional area of the test section) was $12.6 \%$; for comparison, the cylinder in parallel flow considered by Driver ${ }^{9}$ corresponded to a geometric blockage of $16.6 \%$ at the test-section inlet. Structured, axisymmetric grids were created in Pointwise ${ }^{\circledR}$ V17.3 for the intended test conditions using a wedge-shaped domain. The body grid was rotated about the axis of revolution by 1.0 degree, with symmetry boundary conditions imposed on the side planes of the resulting domain. In order to provide a finite width to grid elements upstream of the leading-edge stagnation point, thereby avoiding a line of poles, the axis of revolution was offset below the $z=0$ axis by a distance of $\Delta z / R_{\max }=-0.002$. The finest grid ("F") used a total of 449 points distributed over the body profile in the streamwise direction, with a viscous layer containing 97 points distributed normal to the surface according to a hyperbolic tangent profile (growth factor $=1.05$ ). Flow solutions confirmed the first grid point off the body being below $z^{+}=0.15$ along its entire length for the finest grid. In the radial direction between the edge of the viscous body layer and the tunnel wall boundary, 193 grid points were distributed to represent the outer flow, where the tunnel wall boundary was treated with a viscous layer using 145 points in the wall-normal direction with a hyperbolic tangent distribution (growth factor $=1.05$ ). Figure 3(a) displays the fine grid construction in the vicinity of the body. The grid extended upstream from the nose leading-edge to the physical entrance of the test section located at $x / R_{\max }=-22.8$, corresponding to a length of 55.0 inches $(21.7 \mathrm{~cm})$, and the outflow boundary was located at the termination of the afterbody $\left(x / R_{\max }=7.6\right)$. Physical support hardware (e.g., sting support) was not included in the domain. A total of 309,011 points comprised the wedge domain (body and upstream segment of the test section). A subsonic inflow boundary condition was imposed by specifying total pressure ratio $\left(p_{t} / p_{\infty}=1.00962\right)$ and total temperature ratio $\left(T_{\mathrm{t}} / T_{\infty}=1.00274\right)$, while the outflow condition was specified by setting the static pressure ratio (back pressure $\left.p / p_{\infty}=0.998\right)$ such that the desired inflow Mach number of $M \sim 0.117$ at a point near the entrance to the domain was achieved. In this way, a uniform inflow profile was provided in all cases. The outflow condition required that no reverse flow was present at the exit boundary, which was satisfied in the reported cases. The outer wall boundary was treated with the no-slip condition in all cases other than when studying the explicit effect of the tunnel wall 


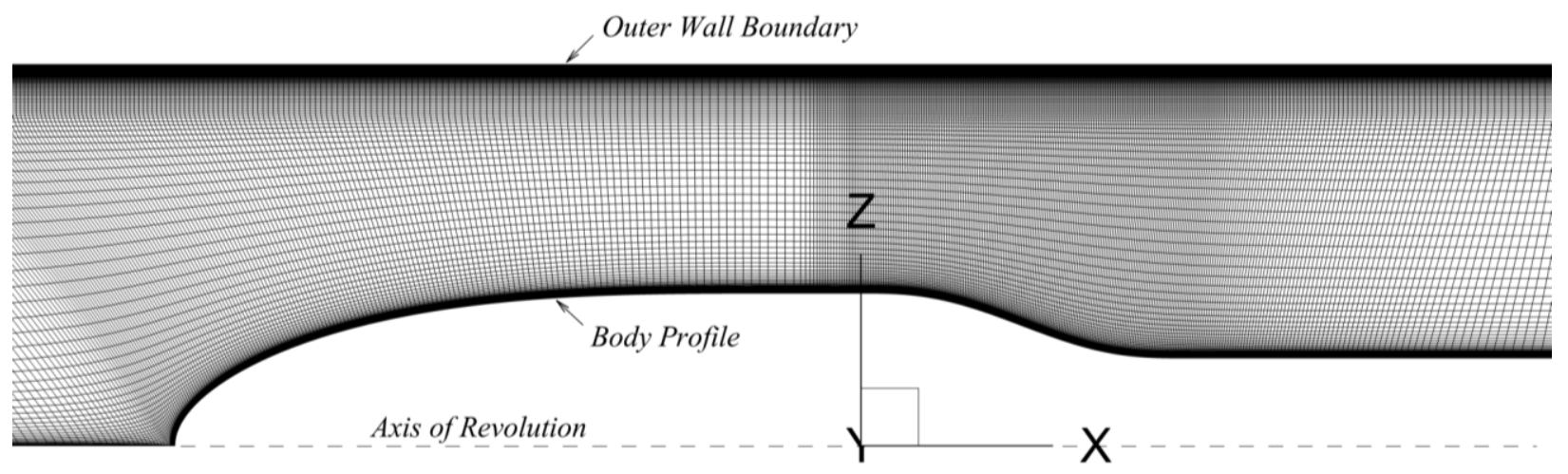

a)

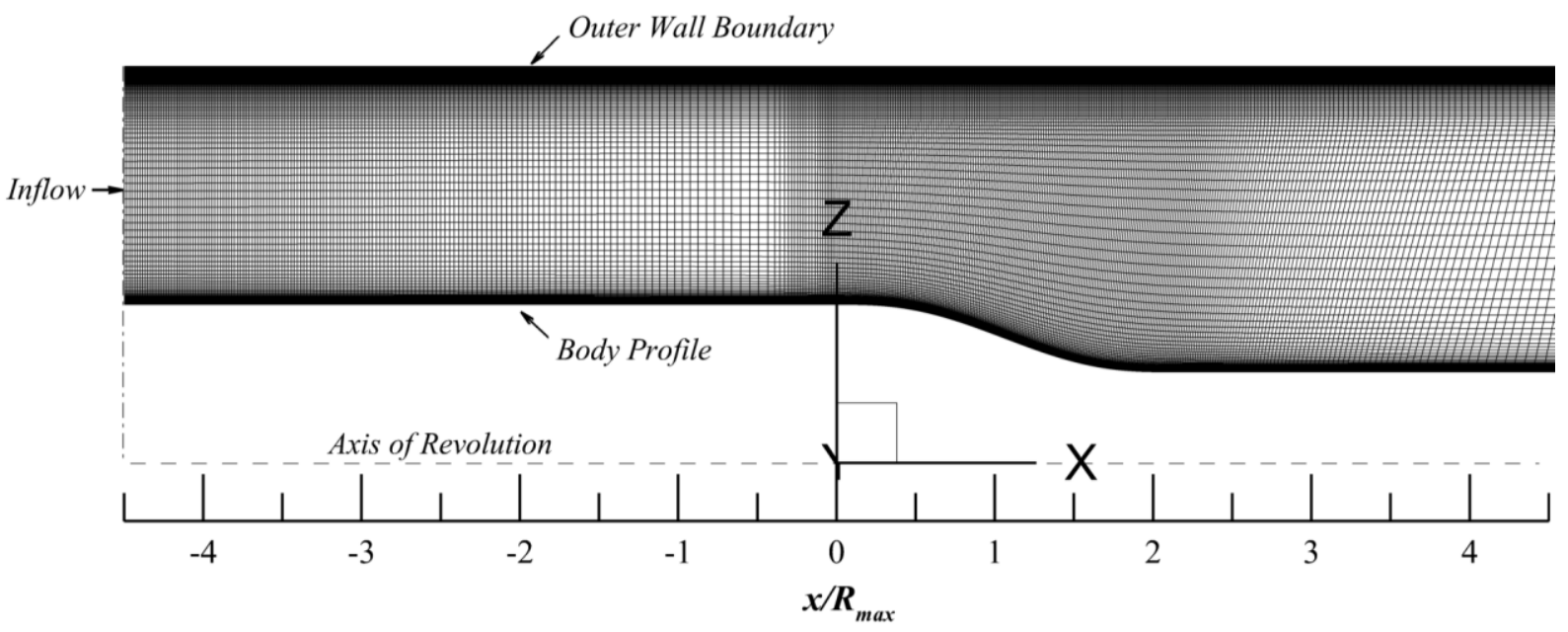

Figure 3. Computational grid (a) in vicinity of body with nose and (b) noseless body. Flow direction is left to right.

boundary-layer on the afterbody flow, in which case the outer wall boundary was treated with an inviscid tangency condition.

In order to study the effect of nose geometry on the afterbody flow behavior, the limiting case of a "noseless body" concept was pursued. The elliptical nose section of the body was replaced by a constant-radius segment having identical axial length and grid point distribution as the elliptical nose, essentially representing an upstreamextension of the constant-radius forebody section. The fine grid construction for the noseless body is shown in Fig. 3(b). This concept required the inflow plane to be located at the start of the constant-radius segment replacing the nose, while the outflow plane remained the same as for the body with nose. The axis of revolution was taken as $z=0$ for the noseless body in order to create a wedge-type domain using the same boundary condition setup as for the body with nose. With the truncated entrance length, a total of 259,522 points comprised the noseless domain.

\section{B. Grid Resolution and Solver Comparison Study}

An assessment of grid resolution was conducted by considering the results from a single turbulence model (SARC) using a coarsening factor of two between successive grid levels. Two coarsening levels below the fine grid were primarily considered, identified as medium $(M)$ and coarse $(C)$. In addition, the resulting grid family was input to two CFD solvers in order to assess code-to-code differences. The two solvers considered were CFL3D ${ }^{22}$ (V6.7) and FUN3D ${ }^{23}$ (V12.9), both developed at NASA. The grid convergence and code-to-code comparisons were cast using skin friction coefficient $C_{f}$ along the boattail length for the body with nose. These results are shown in Fig. 4, with the associated boattail region depicted at top. The difference between grids $M$ and $C$ is larger than the difference between grids $M$ and $F$, with the results from grid $F$ essentially overlaying those of grid $M$. Taken together for both codes and finer grid levels considered, extremely small differences in $C_{f}$ appear in the region of flow relaxation 


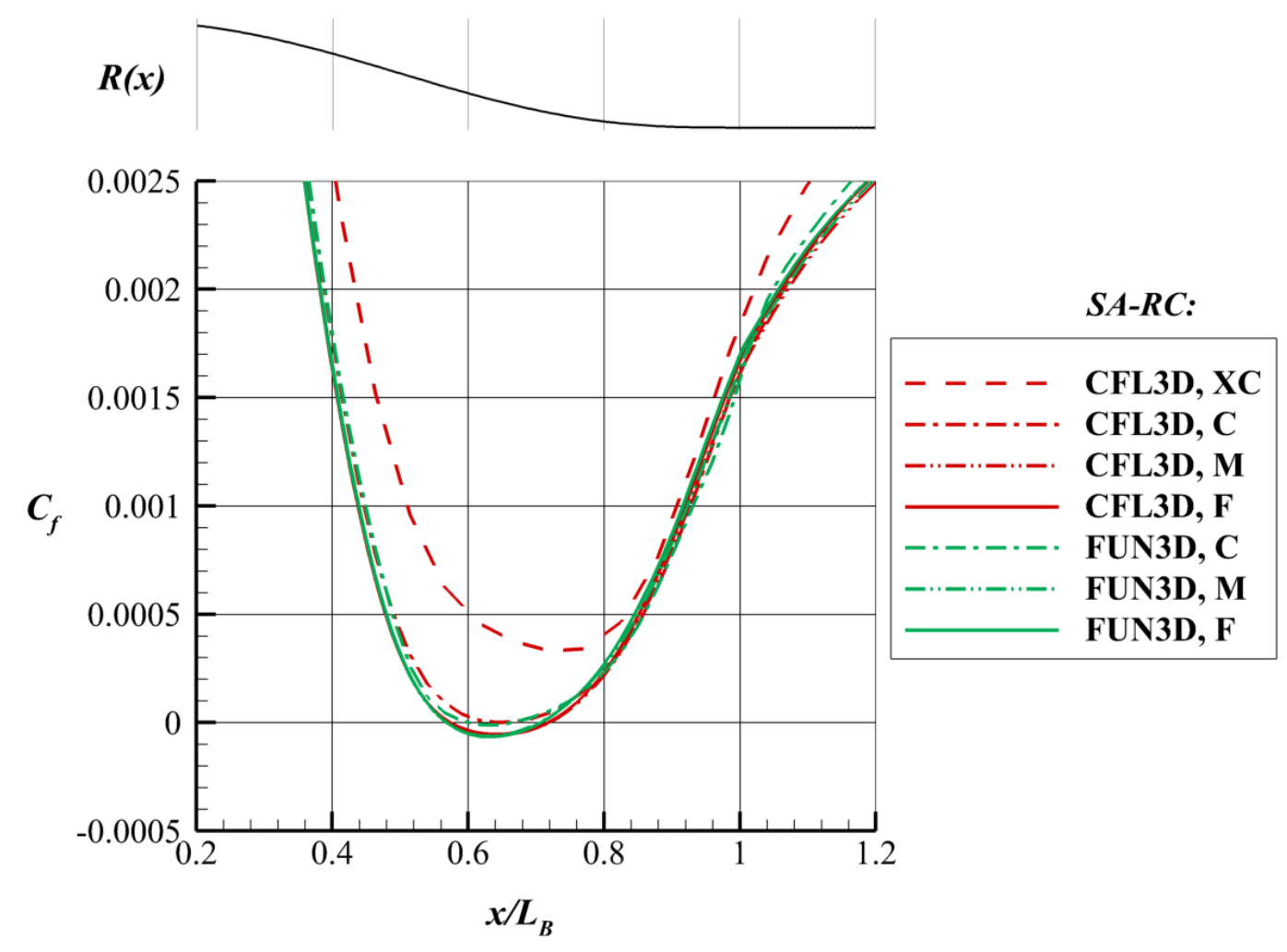

Figure 4. Grid resolution and CFD code comparison results for $C_{f}$ over boattail region using SA-RC turbulence model.

toward the end of the boattail. An extra-coarse $(X C)$ grid computed by CFL3D is shown for reference to further demonstrate the effect of coarsening, in which the $C_{f}$ value does not approach zero as closely as the finer grids. Having demonstrated the level of agreement for the two considered codes, FUN3D was used for the remainder of the reported results.

\section{Representative Flowfields}

To provide a basis for results described in the remainder of this section, representative flowfields for the riskreduction configuration as well as the conceptual body without nose were computed using the SA-RC turbulence model, and are shown in Fig. 5. Both on-body and off-body flows are plotted, cast in terms of skin-friction coefficient and streamwise Mach number $\left(U / a_{\infty}\right)$ contours, respectively. Streamlines are also plotted for the off-body flow.

For the body with nose, the flow accelerates around the nose region until the solid blockage of the forebody section becomes approximately constant. At a distance of $R_{\max }$ upstream of the start of the boattail section (i.e., $\left.x / R_{\max }=-1.0\right)$, the boundary layer thickness was determined to be $\delta=0.13$ inch $(3.4 \mathrm{~mm})$, corresponding to a local $\delta / R=0.045$. For the noseless body, the same station yielded a larger $\delta=0.19$ inch $(4.8 \mathrm{~mm})$; this difference compared to the nose case is attributed to the thinning effect of the favorable pressure gradient associated with the rounded nose. The location of numerical transition, near which the turbulent eddy viscosity begins to exceed the molecular viscosity, was found to occur at approximately 1.0 inch $(2.54 \mathrm{~cm})$ downstream of the nose tip in each of the turbulence models for the body with nose.

Near the start of the boattail $\left(x / R_{\max }=0\right)$, the flow accelerates due to the local convex curvature as $C_{f}$ increases. The flow then decelerates over the boattail in the presence of concave curvature while accommodating the increasing pressure gradient, as $C_{f}$ drops to near zero-indicating flow on the verge of separation. The calculated flow over the outer boundary wall does not indicate separation. After the boattail, the relaxing flow carries a larger momentum deficit while $C_{f}$ increases downstream. The local boundary-layer thickness is approximately $\delta=0.59$ in. $(15.0 \mathrm{~mm})$ for the nose-body at $x / R_{\max }=4.0$, corresponding to $\delta / R=0.34$. Qualitatively, it is observed that the flowfield solutions for both body configurations are very similar. 

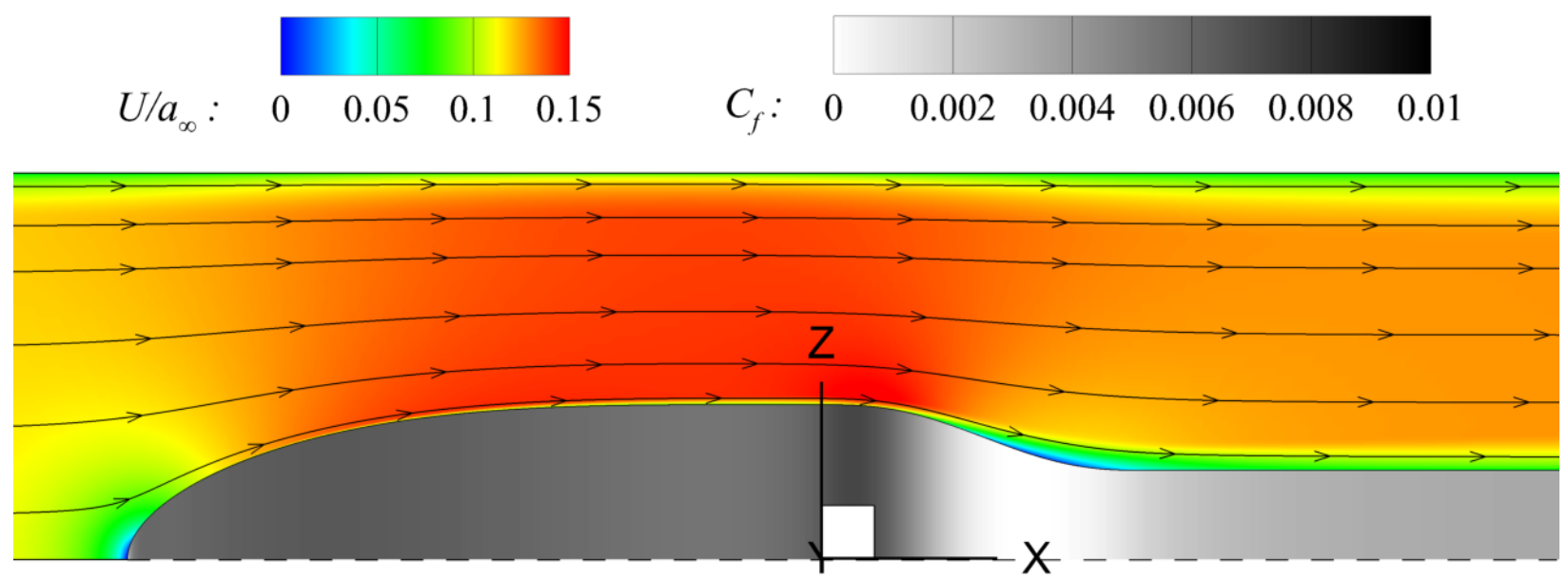

a)

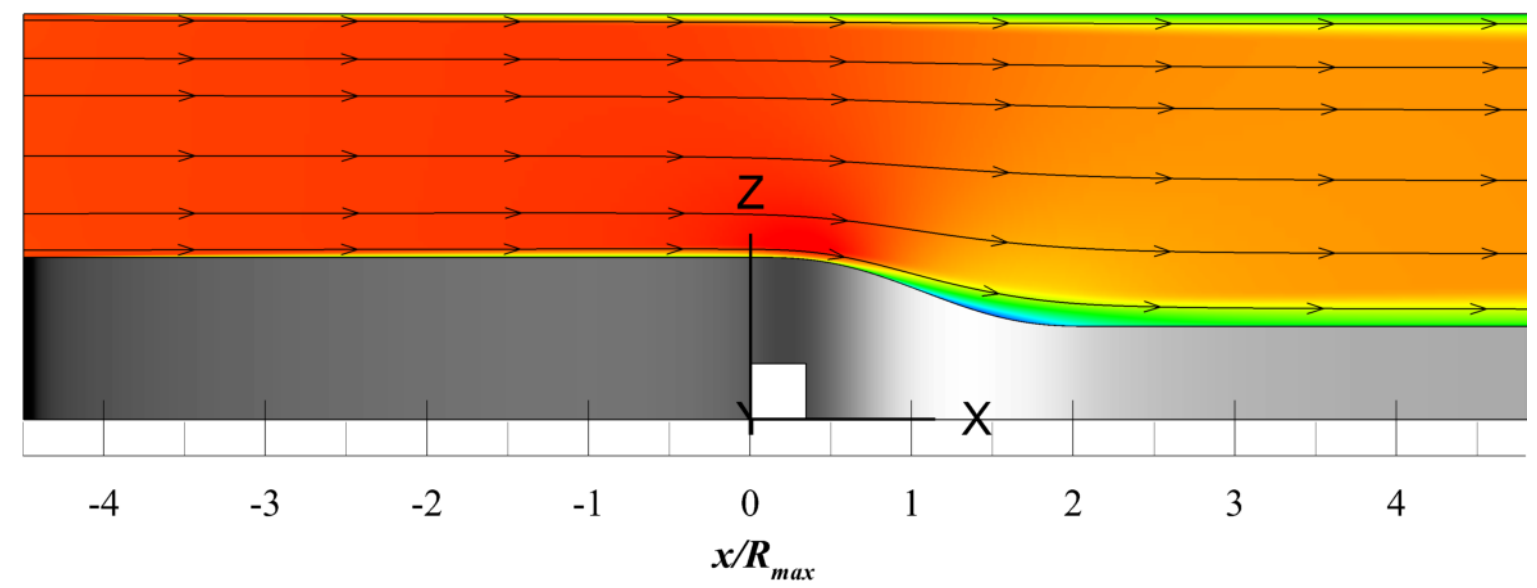

Figure 5. Representative on/off-body flow using SA-RC turbulence model: (a) with nose; (b) without nose.

\section{Turbulence Model Comparison: Effect of Nose}

An ensemble of turbulence models implemented in FUN3D was studied to assess variability in the flow solutions. Seven turbulence models were considered, ranging in complexity from one-equation models to full Reynolds stress models (RSMs). The ensemble of models included the Spalart-Allmaras model ("negative" version, SA-neg), SA-neg with rotation/curvature correction (SA-RC), Menter's standard SST two-equation model (SST), Wilcox's two-equation k- $\omega$ model (Wilcox2006), the k-kL model from Menter/Egorov and Abdol-Hamid (k-kLMEAH2015), as well as the seven-equation, omega-based Reynolds stress models consisting of Wilcox's RSM (WilcoxRSM-w2006) and the SSG/LRR-RSM-w2012 model. For complete formulation details, the reader is referred to the compendium of models at the NASA Langley Turbulence Modeling Resource $\$$. (The above model abbreviations follow the convention of the NASA Langley Turbulence Modeling Resource.) In each case, no "tuning" of model parameters was conducted; the default model parameters as implemented in FUN3D V12.9 were accepted.

As implemented in FUN3D V12.9, the RSM cases required the symmetry planes of the numerical domain to be aligned with Cartesian axes. This required the two RSM cases to be computed on quarter-plane symmetric domains rather than the wedge domains described previously. For this purpose, the wedge domain was rotated about the axis of revolution with azimuthal step increments of $5.0^{\circ}$ to encompass a total angle of $90^{\circ}$ for the RSM cases. Due to the

\footnotetext{
*URL: http://turbmodels.larc.nasa.gov
} 
increased number of grid points and available computing resources at the time of this work, the RSM cases were only calculated for the noseless body concept.

For compactness, the solution associated with each turbulence model considered is presented for the body with nose and without nose in the following discussion. Figure 6 presents the results cast in terms of pressure coefficient along the body beginning at $R_{\max }$ upstream of the boattail section, with the body geometry associated with the given axial limits plotted at the top. The solution in each case was fully converged, with residual levels at $10^{-15}$ or less (including the RSM cases). Cases with the noseless body are denoted by the dashed line, while a solid line of the same color represents the accompanying nose-body result using the specified turbulence model. The flow conditions between the nose/noseless body cases at $x / R_{\max }=-1.0$ differ as expected, yet all the models and nose cases show qualitative agreement as the flow accelerates near the start of the boattail $\left(x / R_{\max }=0\right)$. Taking together all the cases shown, the standard deviation of peak $C_{p}$ near the boattail start is within $1 \%$ of the average result $(0.93 \%)$, affirming that the different flow solutions are in close agreement at this station on the body. Inspection of the skin-friction distribution in this region, shown in Fig. 7, indicates a larger variance in peak $C_{f}$, yet still within $3.5 \%$ of the average result. Following the region of acceleration, the flow over the afterbody decelerates under an adverse pressure gradient, in addition to the effect of streamline convergence present with decreasing body diameter. In this region, the effect of the body nose for a given turbulence model is within the variation observed in peak $C_{p}$. However, the variation between turbulence models is much larger in the adverse pressure gradient region. This type of behavior in achieving close agreement at an effective inflow plane followed by divergence among turbulence model solutions downstream is the basic goal of the present validation test case design.

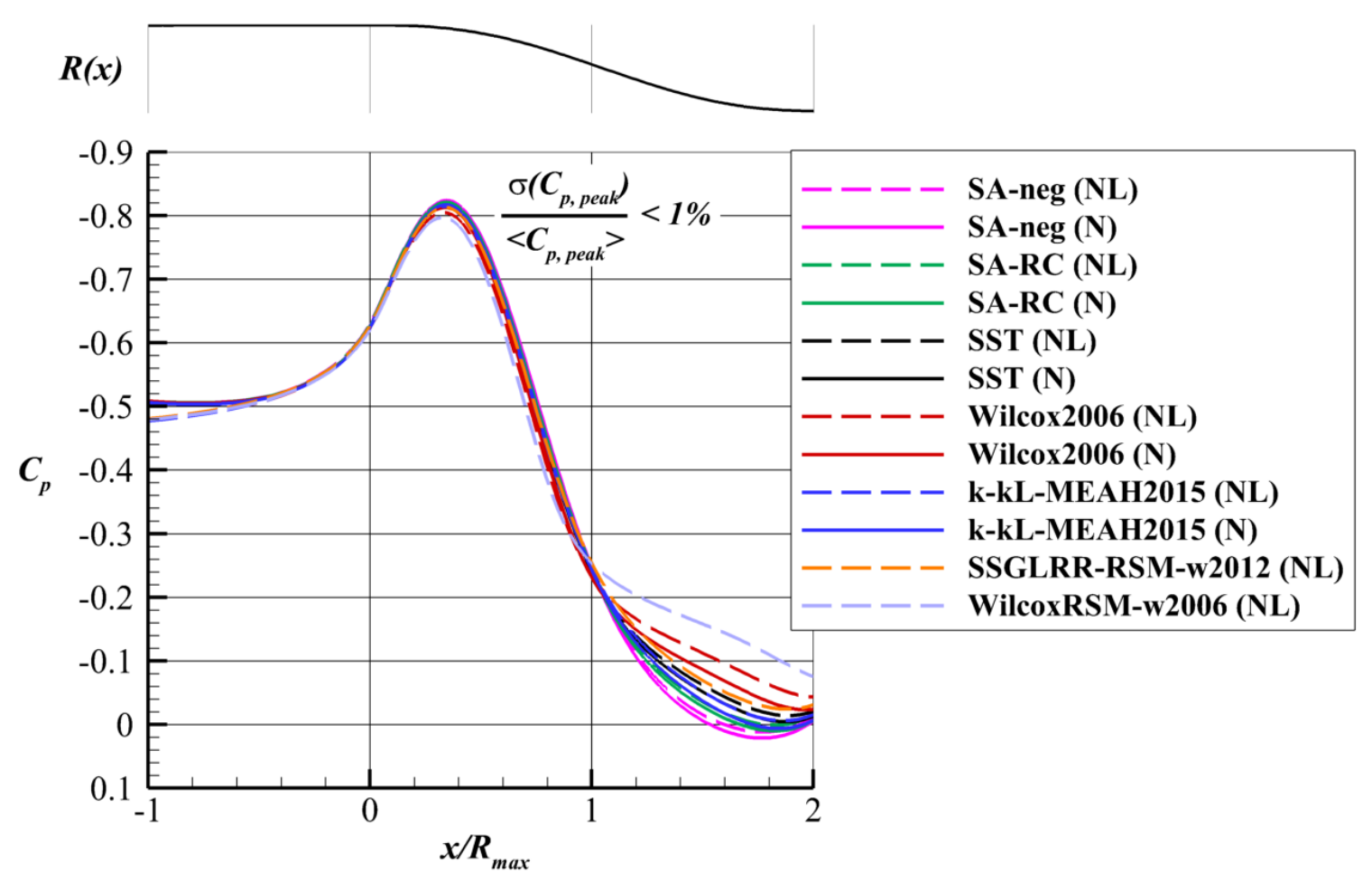

Figure 6. Pressure coefficient distribution in vicinity of boattail section for nose $(\mathrm{N})$ and noseless $(\mathrm{NL})$ bodies using range of turbulence models.

Focusing on the afterbody flow, the skin friction distribution is shown in Fig. 8. Without devoting detailed attention to model form differences, two aspects of the data are noteworthy. First, critical differences in flow separation behavior are shown for the range of turbulence models tested. On the basis of $C_{f}$, these behaviors range from attached flow to small separated flow, with several models on the verge of separation showing fine differences in the existence of reversed flow. (Appealing to the two-dimensional limit, $C_{f}<0$ is taken to indicate reverse flow.) 


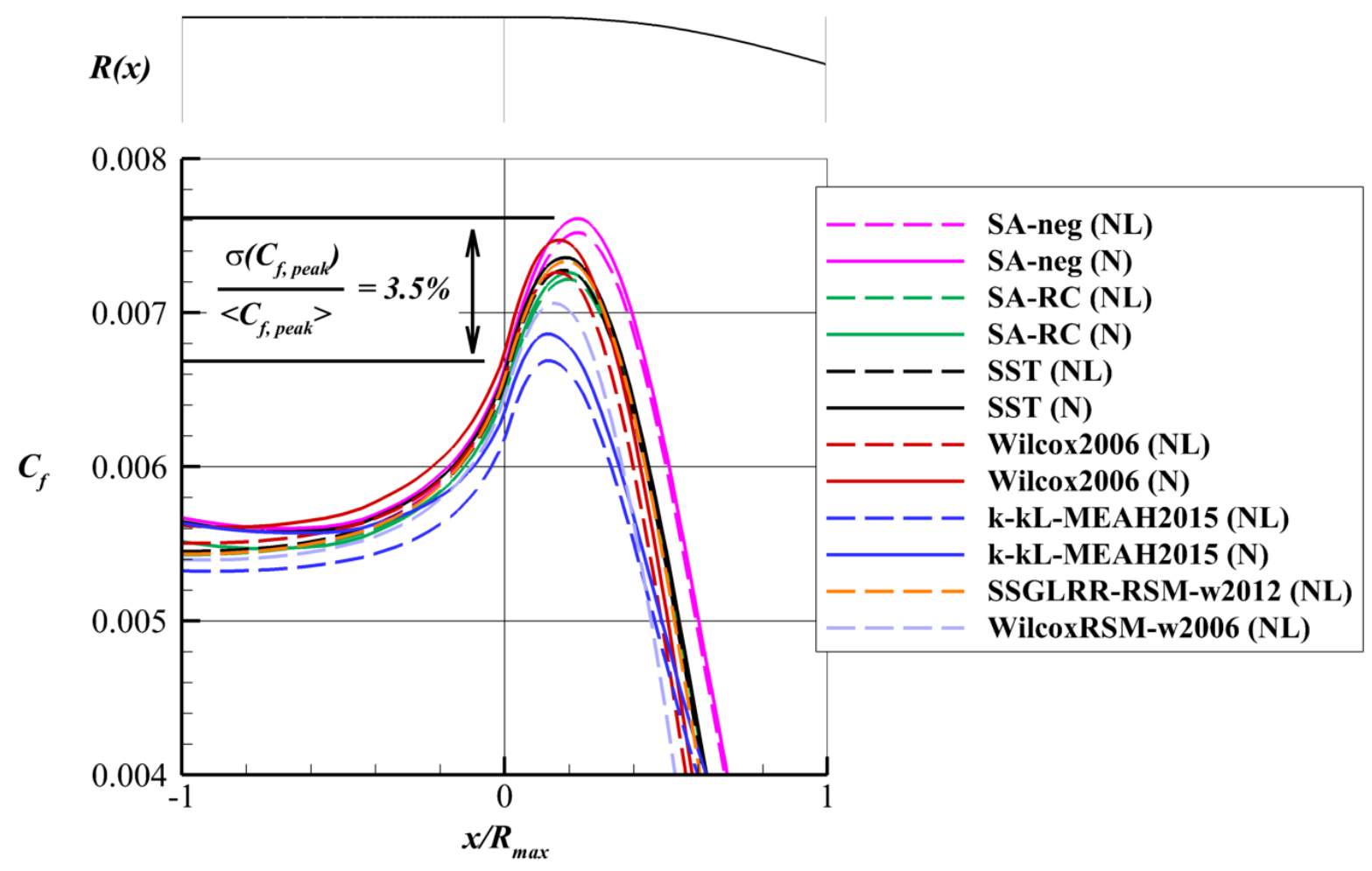

Figure 7. Skin friction distribution near initiation of boattail section for nose (N) and noseless (NL) bodies using range of turbulence models.

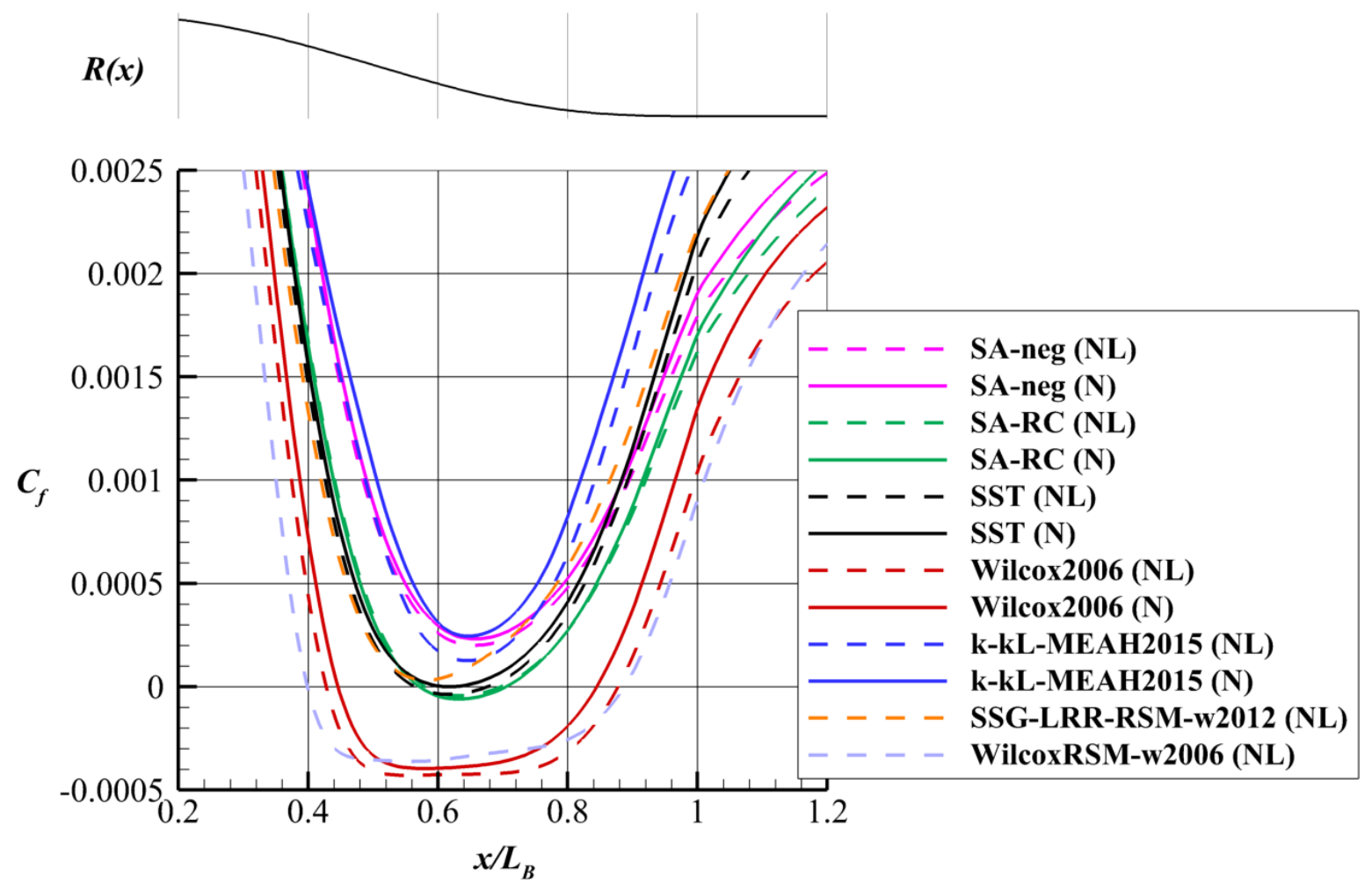

Figure 8. Skin friction distribution on afterbody for nose $(\mathrm{N})$ and noseless (NL) bodies using range of turbulence models. 
Second, the effect of the body nose (with/without) for a given turbulence model is smaller than the overall range of difference among turbulence models; the largest difference due to nose geometry is observed in the relaxation region where $C_{f}$ begins to increase again.

The Wilcox k- $\omega$ model as well as the omega-based RSM (WilcoxRSM-w2006) both indicate the largest extent of separation. For the nose-body case, SA-RC indicates barely-reversed flow, while SST barely fails to indicate reversed flow. The SA-neg model (without rotation/curvature) and k-kL-MEAH2015 models - which bracket the maximum and minimm limits of peak $C_{f}$ variation shown previously in Fig. 7, respectively — both indicate attached flow. The other RSM studied (SSGLRR-RSM-w2012) for the noseless body case indicates flow momentarily on the verge of separation prior to relaxation.

The above ambiguity in afterbody flow behavior suggests that the boattail geometry is an excellent candidate for challenging the models. A "truth case" in the form of experimental measurements or direct numerical simulation (DNS) is needed to assess the accuracy of the models. Inspection of the Reynolds shear stress profiles at station $x / L_{B}=0.625$ indicated that the peak value of $\left\langle u^{\prime} w^{\prime}\right\rangle$ was located at an approximately constant height of $4.0 \mathrm{~mm}$ above the local surface; this site should be accessible with laser-based measurement methods, such as particle image velocimetry. Finally, the fact that the nose geometry (i.e., body with/without nose) did not fundamentally change the ambiguity in flow behavior on the boattail should be encouraging for implementation in higher-fidelity simulations such as DNS and large-eddy simulation (LES). With generation of turbulence at the inflow plane being a challenging task ${ }^{24}$, the noseless-body concept may facilitate implementation of such schemes compared to a stagnation-point calculation for the body with nose. For the goal of model validation, conceptual geometries based on the noseless body could prove to be fruitful for building databases that encompass the strain effects at play for the afterbody.

\section{E. Turbulence Model Comparison: Effect of Tunnel Wall Boundary Layer}

Given the compact flow domain and relatively large model-to-tunnel-size ratio for the risk-reduction configuration, a study focused on the impact of the wind tunnel wall boundary-layer on afterbody flow behavior was conducted. Here, the term "wind tunnel wall" is used loosely, as the numerical domain is in fact an axisymmetric approximation to the physically square test-section geometry; in addition, the boundary layer thickness does not identically match the physical configuration, as the wind tunnel contraction/upstream leg was not included in the domain. For the purpose of study, the same grid for the body with nose was utilized while only changing the outer wall boundary condition from no-slip to slip. In nearly all cases with outer-wall slip, the flow solution was fully converged with residual levels at $10^{-15}$ or less. This property was not satisfied for the SA-RC case with outer-wall slip, as the residuals failed to asymptote or diminish below $10^{-9}$. The convergence difficulty was traced to the numerical transition zone near the leading-edge of the nose, where turbulent eddy viscosity is on the order of the molecular eddy viscosity. However, the flow over the remainder of the body was well-behaved and deemed to be suitable for inclusion with the results.

Results comparing outer-wall boundary condition (slip/no-slip) with the nose-body are plotted in Fig. 9. Results for the slip tunnel wall are shown as dashed lines, while a solid line of the same color for a given turbulence model denotes the viscous tunnel wall case. It is evidenced that the effect of the tunnel wall boundary layer for a given turbulence model is smaller than the overall range of difference among models. Comparison with the results shown previously in Fig. 8 suggests that the effect of the outer-wall boundary layer alone is smaller than the combined effect of the nose geometry and truncated entrance domain in the noseless body case. (Recall that the noseless body results in Fig. 8 also incorporate a thinner outer-wall boundary layer due to the truncated entrance domain.) This suggests that reduced computational expense through inviscid treatment of the outer wall is possible without fundamentally altering the variation among turbulence model results for this case.

\section{Conclusions and Future Work}

The development of a new CFD validation platform based on a parametric body-of-revolution, referred to as the NASA Axisymmetric Afterbody, was presented in this work. A six-parameter body with continuous second derivative of the surface definition was detailed for studying a range of smooth-body turbulent flow cases, varying from attached to separated boundary-layer behavior. The afterbody flow includes combined effects of curvature, adverse pressure gradient, and streamline convergence having practical importance in aerospace industry applications. Critical ambiguity in computed flow behavior for a selected risk-reduction configuration was documented using a range of RANS turbulence models implemented in FUN3D. Turbulence model results ranged from barely-attached to mild separated flow for the described configuration. Exploration of the effects of body nose 


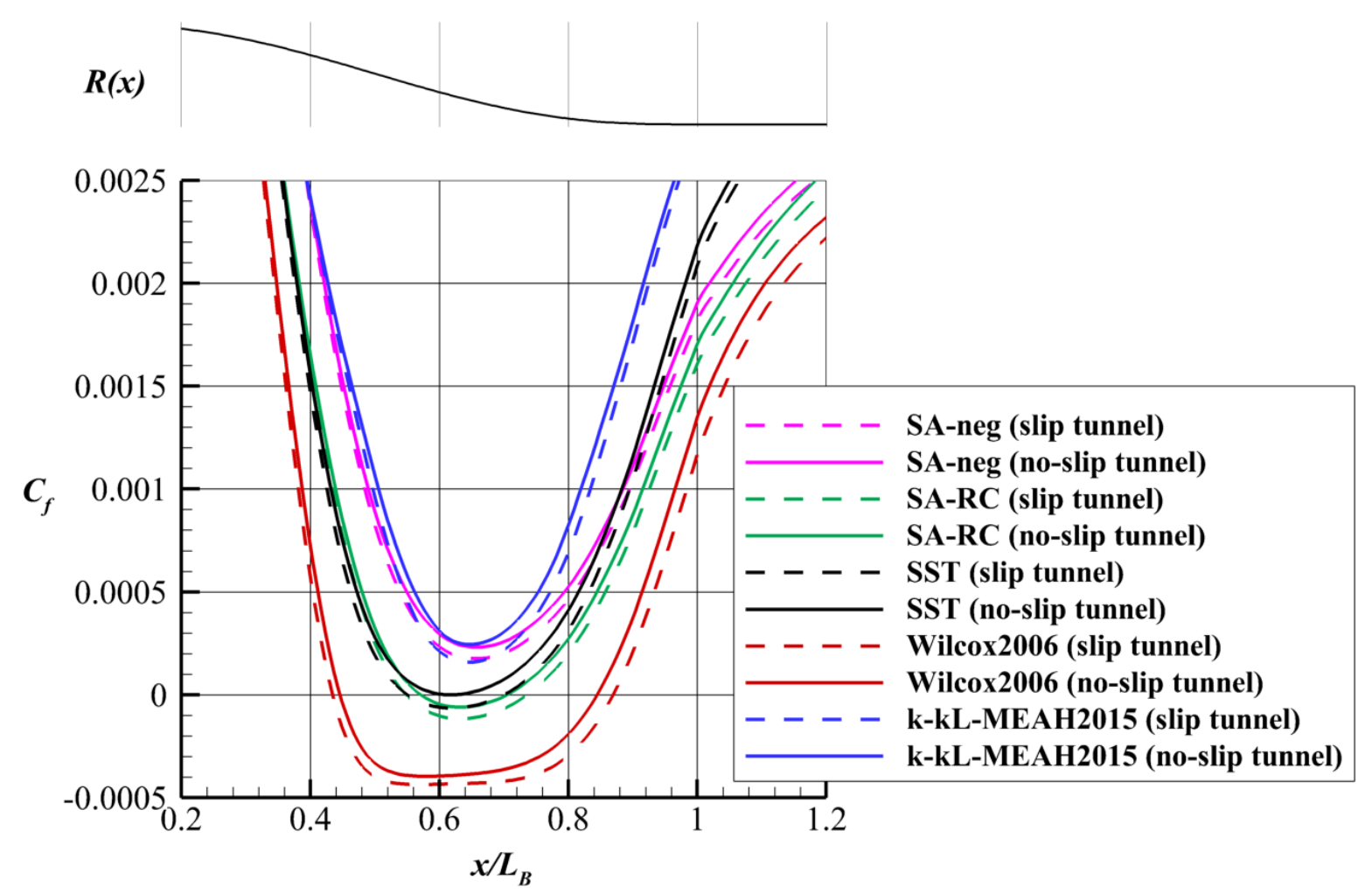

Figure 9. Skin friction distribution on afterbody for cases of outer-wall slip and no-slip conditions with range of turbulence models.

(with/without) as well as the tunnel boundary-layer (with/without) on afterbody flow behavior demonstrated that fundamental differences between turbulence models were larger than either of these factors.

Taken together, the results reported herein demonstrate that the studied afterbody configuration can serve as a discriminating test case for turbulence models aimed at improving near-and-beyond separation behavior. A "truth case" must now be pursued to assess the a priori turbulence model results. Based on the RANS computations described in this work, it was evidenced that the test case can be suitably adapted for either an experimental test campaign using the body with nose, or conceptualized for scale-resolving simulations (LES/DNS) using the noseless body. The parametric body-of-revolution can also serve as a multirole platform by virtue of its interchangeable afterbody, which may be facilitated by "slip-on" component configurations. Such a platform would allow higher Reynolds number testing across a parametric space to generate an encompassing CFD validation database for turbulence modelers.

\section{Acknowledgments}

This research is supported by the appointment of K.J. Disotell to the NASA Postdoctoral Program at Langley Research Center, administered by Universities Space Research Association through a contract with NASA. The support of this appointment by Mujeeb Malik (technical lead, Revolutionary Computational Aerosciences discipline) and the NASA Transformational Tools and Technologies Project within the Transformative Aeronautics Concepts Program are gratefully acknowledged. Feedback from the AIAA Turbulence Model Benchmarking Working Group was valuable in the initial stages of exploration: Brian Smith (Lockheed Martin), Robert Bush (Pratt \& Whitney), Jim Coder (University of Tennessee), Florian Menter (ANSYS), Scott Murman (NASA Ames), Michael Olsen (NASA Ames), and Philippe Spalart (Boeing). Prof. Flint Thomas (University of Notre Dame) is thanked for collaboration on the polynomial ramp contour, and Dennis Bushnell (NASA Langley) is thanked for his recollection of the Winter-Rotta-Smith body. Jan-Reneé Carlson and William T. Jones (NASA Langley) were instrumental in teaching aspects of FUN3D and grid generation software to K.J. Disotell. Finally, K.J. Disotell acknowledges many helpful discussions with colleagues in the Flow Physics and Control Branch at NASA Langley during this work. 


\section{Appendix}

This appendix provides details for the parametric surface definition of the body herein referred to as the NASA Axisymmetric Afterbody, a shape derived from analytic functions. Following the parametric formulation, details for the initial risk-reduction model geometry are documented.

\section{A. Parametric Geometry Definition}

Four sections comprise the isolated body (i.e., no model support hardware): (1) elliptical nose, (2) constantradius forebody extension, (3) contoured boattail, and (4) constant-radius aftbody. The entire body is specified by six parameters: the maximum body radius $\left(R_{\max }\right)$, the ratio of aftbody radius to maximum body radius $(\sigma)$, and the axial length $(L)$ of the four individual stages. In each definition, the coordinate system assumed below is such that $x$ is the coordinate along the axis of revolution increasing in the direction of the mean flow, and $R$ is the radial coordinate normal to $x$. The axial origin of the coordinate system, $x=0$, is taken as the start of the defining equation for the boattail section; in other words, $x<0$ upstream of the boattail section.

\section{Elliptical Nose Section}

The nose section is designed to smoothly engage the flow near the leading-edge stagnation point. The nose shape is generated from a standard ellipse blended with a fourth-order super ellipse, similar to that used by Watson et al. ${ }^{4}$ in which a third-order super ellipse was blended with a standard ellipse. A fourth-order super ellipse was chosen to reduce the bluntness (in reference to axial distribution of cross-sectional area) of the nose while approaching zero curvature at the cross-over between body segments. The nose definition is given by Eq. (1a) as:

$$
R(x)=r_{1}\left(1-\frac{x+L_{F}+L_{N}}{L_{N}}\right)+r_{2}\left(\frac{x+L_{F}+L_{N}}{L_{N}}\right) ; \quad-\left(L_{F}+L_{N}\right) \leq x \leq-L_{F}
$$

with

$$
\begin{aligned}
& r_{1}=R_{\max }\left[1-\left(\frac{x+L_{F}}{L_{N}}\right)^{2}\right]^{1 / 2} \\
& r_{2}=R_{\max }\left[1-\left(\frac{x+L_{F}}{L_{N}}\right)^{4}\right]^{1 / 4}
\end{aligned}
$$

where $R_{\max }$ is the specified maximum body radius, $L_{N}$ is the axial length of the nose section, and $L_{F}$ is the axial length of the constant-radius forebody section.

\section{Constant-Radius Forebody Section}

The constant-radius forebody section provides a convenient experimental control for incoming boundary-layer properties to the afterbody. It may be extended or shortened to allow for a desired boundary-layer thickness, for example. The right-cylindrical section is expressed by Eq. (2) as:

$$
R(x)=R_{\max } ; \quad-L_{F} \leq x \leq 0
$$

\section{Contoured Boattail Section}

For the boattail, a fifth-order polynomial was selected for its capacity to support three inflection points, two of which are imposed at the end points of the contour to ensure that the first and second derivatives are zero. The boattail section is expressed by Eq. (3a) as:

$$
R(x)=a_{1}+a_{2} x^{3}+a_{3} x^{4}+a_{4} x^{5} ; 0 \leq x \leq L_{B}
$$

with

$$
a_{1}=R_{\max }
$$




$$
\begin{aligned}
& a_{2}=\frac{-10 R_{\max }(1-\sigma)}{L_{B}{ }^{3}} \\
& a_{3}=\frac{15 R_{\max }(1-\sigma)}{L_{B}{ }^{4}} \\
& a_{4}=\frac{-6 R_{\max }(1-\sigma)}{L_{B}{ }^{5}}
\end{aligned}
$$

where $\sigma$ is the ratio of the minimum aftbody radius to the maximum body radius and $L_{B}$ is the axial length of the boattail section.

\section{Constant-Radius Aftbody Section}

The axial length of the constant-diameter aftbody section is intended to be adjustable as needed in order to provide a sufficient relaxation distance for the flow after encountering the boattail section, since measurements of the flow recovery can be of interest. Furthermore, the aftbody length has a practical consideration in providing sufficient separation from the downstream test model support system. The right-cylindrical aftbody section is expressed by Eq. (4) as:

$$
R(x)=\sigma R_{\max } ; \quad L_{B} \leq x \leq\left(L_{B}+L_{A}\right)
$$

From the perspective of wind tunnel testing, a minimum length $L_{A}$ can be suggested by consideration of model support interference effects. With many studies of sting/support interference having been reported in the literature for various sting-mounted bodies, the constant-radius aftbody section attempts to mitigate the influence of the sting by close integration of component diameters, thereby minimizing exposure of a significant base region. An aftbody length $L_{A}$ of at least 5 model base-diameters, where the base diameter referred to here is expressed as $2 \sigma R_{\max }$, is near the lower limit from the interference study of Tunnell ${ }^{25}$. Typical sting mounts may also have a flare, a tapered insert to the model base which precedes the sting shaft to augment structural integrity at the model connection. Here, the sting flare diameter should not exceed the aftbody diameter in order to minimize upstream influence, and struts supporting the sting should minimize frontal blockage.

\section{B. Risk-Reduction Test Model Parameters}

A prototype test model to be built for risk-reduction experiments was guided by CFD calculations that alluded to key variations in flow behavior using different turbulence models. Table 1 lists the parameter set for the riskreduction body. The divergence and curvature parameters of the geometry-being proportional to the first and second derivatives of the longitudinal body profile, respectively - are plotted in Fig. 10. The divergence parameter is $\eta^{\prime} / \eta$, where $\eta=R(x)$ along the body and the prime notation denotes ordinary differentiation with respect to the axial coordinate $x$. The longitudinal curvature is denoted by $\kappa$, given as:

$$
\kappa=\frac{-\eta^{\prime \prime}}{\left[1+\left(\eta^{\prime}\right)^{2}\right]^{3 / 2}}
$$

where the negative is supplied to signify convex curvature as a positive value.

Table 1: Parameter set for risk-reduction body.

\begin{tabular}{|c|c|}
\hline Parameter & Value \\
\hline$R_{\max }$ & 3.0 in. \\
\hline$L_{N}$ & $4.0 R_{\max }$ \\
\hline$L_{F}$ & $0.5 R_{\max }$ \\
\hline$L_{B}$ & $2.1 R_{\max }$ \\
\hline$L_{A}$ & $5.5 R_{\max }$ \\
\hline$\sigma$ & 0.575 \\
\hline
\end{tabular}



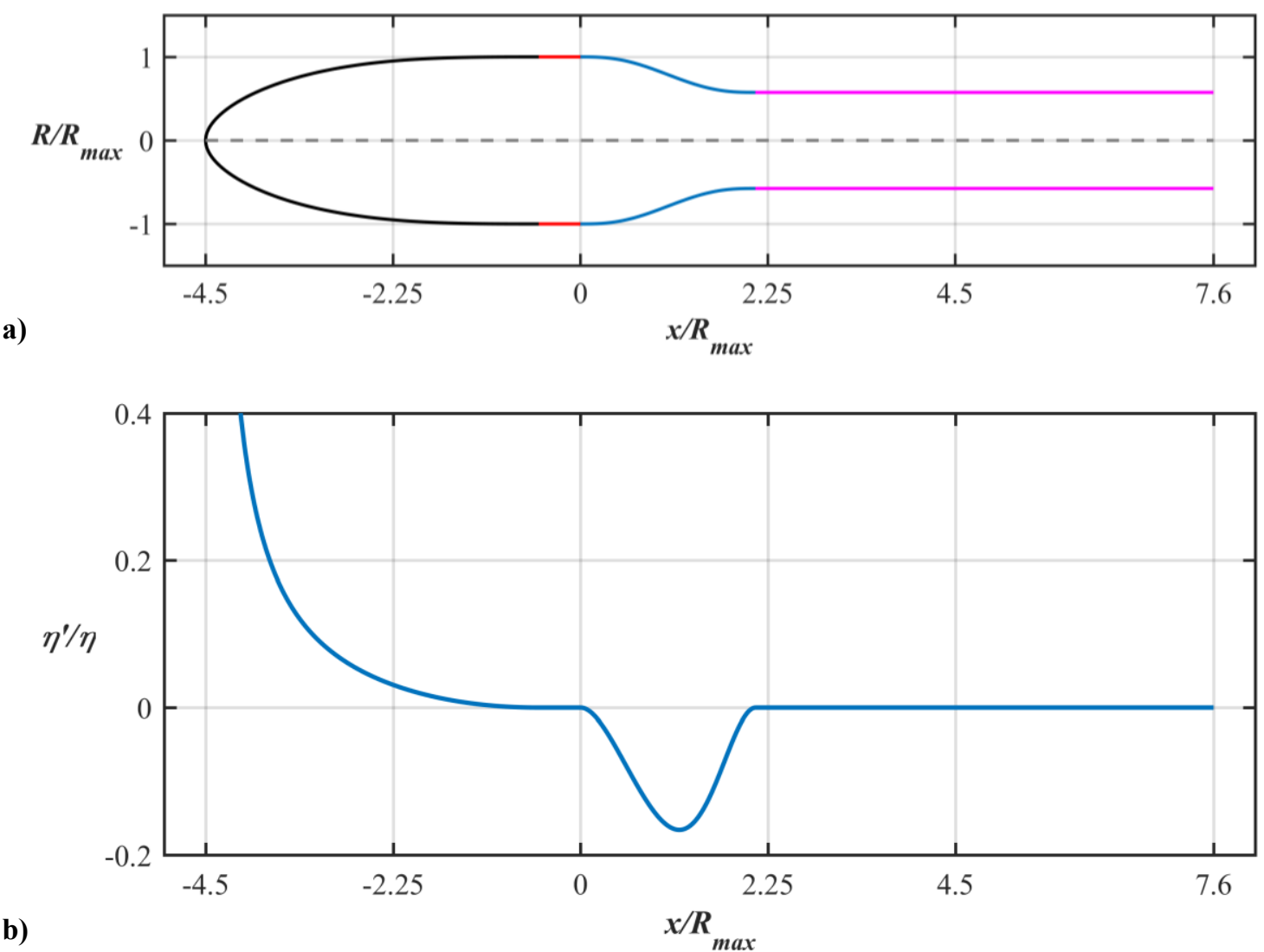

b)

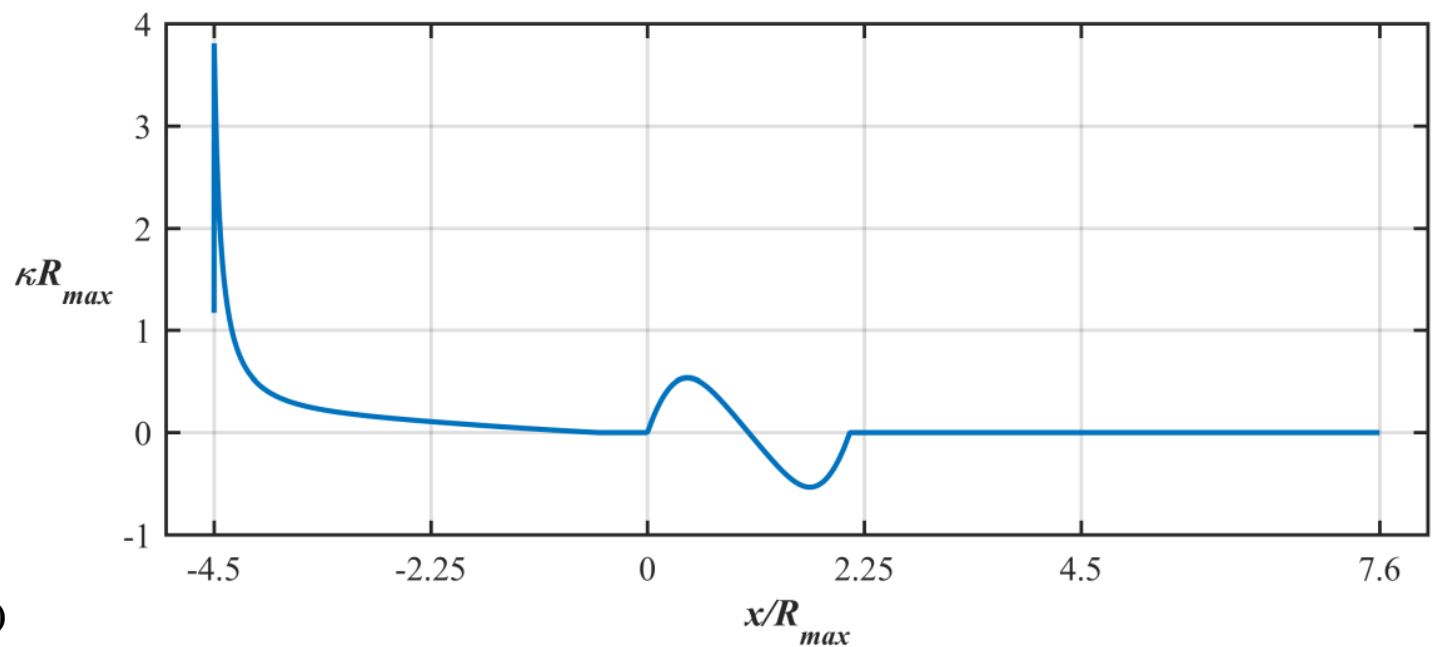

Figure 10. Geometry description for risk-reduction body corresponding to parameters in Table 1:

(a) profile of revolution; (b) divergence parameter; (c) longitudinal curvature.

Note coordinate convention placing $x=0$ at start of boattail section. 


\section{References}

${ }^{1}$ Slotnick, J., Khodadoust, A., Alonso, J., Darmofal, D., Groff, W., Lurie, E., and Mavriplis, D., "CFD Vision 2030 Study: A Path to Revolutionary Computational Aerosciences," NASA CR-2014-218178, 2014.

${ }^{2}$ Rumsey, C.L., Neuhart, D.H., and Kegerise, M.A., "The NASA Juncture Flow Experiment: Goals, Progress, and Preliminary Testing (Invited)," 54th AIAA Aerospace Sciences Meeting, AIAA Paper 2016-1557, 2016. doi: 10.2514/6.2016-1557.

${ }^{3}$ Oberkampf, W.L. and Roy, C.J., "Verification and Validation in Scientific Computing," Cambridge University Press, 2012.

${ }^{4}$ Watson, R.D., Anders, J.B., and Hall, R.M., "Skin Friction at very High Reynolds Numbers in the National Transonic Facility," NASA TP 2006-214497, 2006.

${ }^{5}$ Carlson, J.-R. and Reubush, D.E., "High Reynolds Number Analysis of an Axisymmetric Afterbody with Flow Separation," 19th AIAA Advanced Measurement and Ground Testing Technology Conference, 1996. doi: 10.2514/6.1996-2274.

${ }^{6}$ Fluid Dynamics Panel Working Group 21, "A Selection of Test Cases for the Validation of Large-Eddy Simulations of Turbulent Flows," North Atlantic Treaty Organization Advisory Group for Aerospace Research \& Development, AGARDAR-345, Neuilly-sur-Seine, France, 1998.

${ }^{7}$ Winter, K.G., Rotta, J.C., and Smith, K.G., "Turbulent Boundary Layer Studies on a Waisted Body of Revolution in Subsonic and Supersonic Flow," Aeronautical Research Council R\&M No. 3633, 1970.

${ }^{8}$ Bachalo, W.D. and Johnson, D.A., "Transonic, Turbulent Boundary-Layer Separation Generated on an Axisymmetric Flow Model," AIAA Journal, Vol. 24, No. 3, 1986, pp. 437-443. doi: 10.2514/3.9286.

${ }^{9}$ Driver, D.M., "Reynolds Shear Stress Measurements in a Separated Boundary Layer Flow," 22nd AIAA Fluid Dynamics, Plasma Dynamics, and Lasers Conference, AIAA Paper 91-1787, 1991. doi: 10.2514/6.1991-1787.

${ }^{10}$ Alving, A.E. and Fernholz, H.H., "Mean-Velocity Scaling in and Around a Mild, Turbulent Separation Bubble," Physics of Fluids, Vol. 7, No. 8, 1995, pp. 1956-1969. doi: 10.1063/1.868772.

${ }^{11}$ Alving, A.E. and Fernholz, H.H., "Turbulence Measurements Around a Mild Separation Bubble and Downstream of Reattachment," Journal of Fluid Mechanics, Vol. 322, 1996, pp. 297-328. doi: 10.1017/S0022112096002807.

${ }^{12}$ Presz, W.M. and Pitkin, E.T., "Flow Separation Over Axisymmetric Afterbody Models," Journal of Aircraft, Vol. 11, No. 11, 1974, pp. 677-682. doi: 10.2514/3.60403.

${ }^{13}$ Reubush, D.E. and Putnam, L.E., "An Experimental and Analytical Investigation of the Effect on Isolated Boattail Drag of Varying Reynolds Number Up to $130 \times 10^{6}$," NASA TN D-8210, 1976.

${ }^{14}$ Hammache, M., Browand, F.K., and Blackwelder, R.F., "Whole-Field Velocity Measurements Around an Axisymmetric Body with a Stratford-Smith Pressure Recovery," Journal of Fluid Mechanics, Vol. 461, 2002, pp. 1-24. doi: $10.1017 / \mathrm{S} 0022112002008479$

${ }^{15}$ Smits, A.J. and Wood, D.H., "The Response of Turbulent Boundary Layers to Sudden Perturbations," Annual Review of Fluid Mechanics, Vol. 17, 1985, pp. 321-358. doi: 10.1146/annurev.fl.17.010185.001541.

${ }^{16}$ Parish, E.J. and Duraisamy, K., "A Paradigm for Data-Driven Predictive Modeling using Field Inversion and Machine Learning," Journal of Computational Physics, Vol. 305, 2016, pp. 758-774. doi: 10.1016/j.jcp.2015.11.012.

${ }^{17}$ Xiao, H., Wu, J.-L., Wang, J.-X., Sun, R., and Roy, C.J., "Quantifying and Reducing Model-Form Uncertainties in Reynolds Averaged Navier-Stokes Equations: A Data-Driven, Physics-Informed Bayesian Approach," Journal of Computational Physics, Vol. 324, 2016, pp. 115-136. doi: 10.1016/j.jcp.2016.07.038.

${ }^{18}$ Smits, A.J. and Joubert, P.N., "Turbulent Boundary Layers on Bodies of Revolution," Journal of Ship Research, Vol. 26, No. 2, 1982, pp. 135-147.

${ }^{19}$ Bradshaw, P., "Effects of Streamline Curvature on Turbulent Flow," North Atlantic Treaty Organization Advisory Group for Aerospace Research and Development, AGARD-ograph 169, Neuilly-sur-Seine, France, 1973.

${ }^{20}$ Robinson, R.C., Wilcox, P.R., Gambucci, B.J., and George, R.E., "Dynamic Response of a Family of Axisymmetric Hammerhead Models to Unsteady Aerodynamic Loading," NASA TN D-4504, 1968.

${ }^{21}$ Murman, S.M., Blonigan, P.J., and Diosady, L.T., "Comparison of Transonic Buffet Simulations with Unsteady PSP Measurements for a Hammerhead Payload Fairing," 55th AIAA Aerospace Sciences Meeting, AIAA Paper 2017-1404, 2017. doi: 10.2514/6.2017-1404.

${ }^{22}$ Krist, S.L., Biedron, R.T., and Rumsey, C.L., "CFL3D User's Manual (Version 5.0)," NASA TM-1998-208444, 1998.

${ }^{23}$ Biedron, R.T., Carlson, J.-R., Derlaga, J.M., Gnoffo, P.A., Hammond, D.P., Jones, W.T., Kleb, B., Lee-Rausch, E.M., Nielsen, E.J., Park, M.A., Rumsey, C.L., Thomas, J.L., and Wood, W.A., "FUN3D Manual: 12.9," NASA TM-2016-219012, 2016.

${ }^{24}$ Ferrante, A. and Elghobashi, S.E., "A Robust Method for Generating Inflow Conditions for Direct Simulations of SpatiallyDeveloping Turbulent Boundary Layers," Journal of Computational Physics, Vol. 198, No. 1, 2004, pp. 372-387. doi: 10.1016/j.jcp.2004.01.016.

${ }^{25}$ Tunnell, P.J., "An Investigation of Sting-Support Interference on Base Pressure and Forebody Chord Force at Mach Numbers from 0.60 to 1.30," NACA RM A54K16a, 1955. 